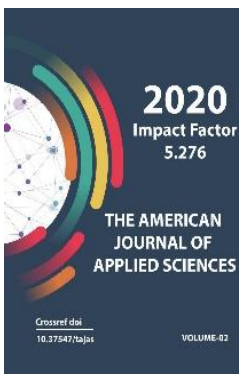

Journal Website: http://usajournalshub.c om/index,php/tajas

Copyright: Original content from this work may be used under the terms of the creative commons attributes 4.0 licence.

\section{On The Importance Of Historicism Elements In Mathematics Lessons In Elementary Grades}

\author{
Gulnara Javlieva \\ Lecturer, Department of Algebra and Geometry, Termiz State University, Uzbekistan \\ Nargiza Muzropova \\ Lecturer, Department of Algebra and Geometry, Termiz State University, Uzbekistan
}

\title{
ABSTRACT
}

The article reveals the importance of historicism elements in mathematics lessons in elementary grades. The author demonstrates opportunities to increase students 'interest in learning mathematics and in-depth study of the facts being studied.

\section{KEYWORDS}

Elements of history, mathematical terminology and symbols, historical materials.

\section{INTRODUCTION}

From the first days of independence, the policy of reforming the education system as a key part of the course of reforms and renewal of society in Uzbekistan has been consistently pursued.

To achieve this goal, the National Training Program was adopted, which provides for “... the implementation of the national model of training, the creation of socio-economic, legal, psychological and pedagogical conditions for the formation of a comprehensively developed personality, adaptation to modern changing society." and is being implemented successfully. This is also stated in the Address of the President of the Republic of Uzbekistan Shavkat Mirziyoyev to the Oliy Majlis:

“... We have set ourselves the goal of joining a number of developed countries and we will be able to achieve it only by carrying out accelerated reforms, relying on science, 
education and innovation. To do this, we, first of all, need to educate cadres of a new formation, who are the initiators of reforms, who have a strategic vision, deep knowledge and high qualifications. That is why we have begun reforming all levels of education - from preschool to higher education.

Science and education are very important to increase the intellectual and spiritual potential not only of young people, but of our society as a whole. Where science is underdeveloped, there is regression and backwardness in all areas of society.

The great thinkers of the East said: "The greatest wealth is reason and science, the greatest inheritance is a good upbringing, the greatest poverty is the lack of knowledge."

The desire to master modern knowledge, be enlightened and have a high culture should become a vital need for all of us."

\section{MAIN PART}

The inseparable interdependence and unity of the tasks of forming the dialectical worldview of students, the tasks of their comprehensive education and development - all this is a conclusion about the appropriateness and expediency of the use of historical and mathematical materials in the study of modern school mathematics allows you to do.

Indeed, the importance of familiarizing students with the history of science is well known for educating students in the spirit of patriotism and internationalism. The example of the life of great thinkers of the past, their scientific and moral convictions can have a strong influence on the processes of selfimprovement and self-education of schoolchildren... For example, the genius scientist Biruni, who is known for outstanding discoveries in the field of astronomy, mathematics, geography, geology, botany, went down in the history of mankind as an outstanding humanist philosopher and poet.
What gave strength to the discoveries of Biruni for the subsequent development of sciences and the practical use of the scientific results obtained by him? There is no doubt that his conviction in the importance of pure knowledge and search for the improvement of man was great. The main thing for Biruni was to learn and understand. Apparently, to put this fact at the heart of the moral beliefs of schoolchildren in the modern teacher should be no less than to acquaint students with his scientific work.

When combined with the study of the educational material of the school mathematics course, historical information is well remembered and, therefore, can serve as a means of memorizing educational information. Here we see how important it is that in the minds of schoolchildren not separate, disparate episodes from the history of the development of mathematics are imprinted, but the process of the formation of its basic ideas and methods. Mathematics should appear before schoolchildren in the creative process of creation and development. It is no less important that the history of science allows students to observe in action the interconnection and interdependence of theoretical scientific knowledge and practical human activity. This contributes to a more effective formation of the dialecticalmaterialistic worldview and scientific thinking of students.

The inclusion of a harmonious system of historical and mathematical information in the process of teaching mathematics, obviously, should mean that the teacher recognizes as legitimate a certain element of amusement and entertainment, which is associated with all sorts of historical curiosities. But entertaining is permissible not only in primary grades, it can be an easy start to a serious, completely scientific conversation that helps students to master the content of the school course, basic ideas, language, methods of 
modern mathematical science, methods of creative mathematical activity.

Pedagogy teaches that when presenting new educational information to students, it is advisable to use all ways of forming cognitive interest. An entertaining presentation of new mathematical facts and phenomena, as the practice of the best teachers of mathematics in the country shows, never harmed the subsequent disclosure of their essential properties, and then showing the cause-andeffect relationships, general principles operating in various conditions.

I. Kadyrov quite rightly asserts in his book "The relationship of extracurricular and extracurricular activities in mathematics" (M., Prosveshchenie, 1983) that all or almost all sections of the optional course can and should be studied with the involvement of historical and mathematical material. He distinguishes between several uses of historical material in the process of teaching mathematics:

1. An episodic excursion into the history of mathematics; origin of the term, reference to the discoverer of a formula, theorem or method.

2. A longer conversation, sometimes in connection with the listed elements, for example, a story about the views of the Pythagorean school, solving a historical problem.

3. Review of the life and work of certain outstanding mathematicians (Archimedes, Abu Rayhan al-Biruni, N.I Lobochevsky, etc.).

4. A review of mathematical results obtained in a certain era or related to the development of certain mathematical theories, for example, to computational mathematics and computers.

5. Generalization and systematization of students' knowledge with the help of an in-depth historical review, which analyzes the development of one or another content line of the school course. Of course, there are many more theoretically possible such types. Let's take the grounds for classifying the use of historical material in mathematics lessons:

- Message - fact, brief historical information.

- Message - a story about interconnected historical facts, often accompanied by a consideration of illustrative material, analysis and solution of historical problems, etc. (due to which this view is also called conversation).

- Message - a review that provides an indepth analysis of the development of a certain branch of mathematics, the formation of its ideas and methods.

\section{In terms of timing, this statement reflects:}

- "Vertical" section (with a characteristic of the historical development of one or another branch of mathematics).

- "Horizontal" cut (with a characteristic of a certain historical era).

- The life and work of one or another great mathematician of the past (personalities).

Various combinations of these types (we are not yet considering the practical benefits of each of them) increase their number to 9, but we have not yet considered the types of use of historical and mathematical material, depending on its cognitive, educational, methodological, developmental and even educational purpose. ...

However, a formal analysis of each of the combined uses of historical material, in our opinion, will not give new results, significantly complicating the presentation. Taking this into account, and also taking into account the dominant educational (educational) function of using historical material in mathematics lessons, conclusions about the most appropriate types of it should be made based 
on an analysis of its specific connections with educational material.

The analysis of the various functions of using historical material is of much greater importance, since the conclusions obtained will affect the methodology of the teacher's work. In the methodological literature, this issue is not given due attention, being limited mainly to the methodological function and the explanation of the influence of historical and mathematical material on the development of the cognitive interest of students.

A textbook on mathematics, apparently, can contain a modern interpretation of any mathematical concept, doctrine and theory. But in the teacher's explanation, in the content of his conversation, the history of mathematics should also find a place. Such a presentation of a topic, a section can be made economical in time, based, say, on the independent home study by students of the historical and mathematical texts of mathematics textbooks or corresponding articles in a mathematical wall newspaper. But the teacher will benefit in the availability of his explanation, in the formation of students' interest in the study of mathematics, in the history of science and the country, in outstanding personalities of the past, living for centuries and millennia in the people's memory.

\section{RESULTS AND DISCUSSION}

To implement the principle of historicism in the presentation of the initial educational information in the process of teaching mathematics at school does not mean a cursory mention of two or three names of scientists. We are talking about the constant striving of the teacher to reproduce in his explanation the historically conditioned process of the emergence and evolution of certain mathematical objects so that this corresponds to the interests of the students' assimilation of the textbook content.

An important didactic concept of educational practice should include (in accordance with the considered features of teaching mathematics) not only direct practical and educational applications of the course, but also all intermediate stages of mathematical abstractions, all within the subject and interdisciplinary connections of the mathematics course. A didactic model of the dialectical path of cognition, in our opinion, is such a construction of the educational process in which the educational practice of schoolchildren acts in relation to the studied theoretical information: 1) the source of their appearance; 2) a means of verifying the truth (or purely educational value, for example, for mastering related subjects); 3) the area of application (in practice, in mathematics itself, again in academic subjects related to mathematics, etc.).

The didactic interdependence of the theoretical knowledge of mathematics and the practical work of students related to learning really helps the teacher to show students both the objective connections of science with life and the internal logic of the development of their educational and cognitive work in the study of mathematics.

\section{Historical Material on the Topic "Values"}

It's hard to imagine everyday life without measuring different quantities. Even in primitive society, people used different dimensions to build a house: the width, height, size of the dwelling, and so on.

The first means of measuring length were parts of the human body: fingers, palm, step and others. In ancient Egypt, the main means of measuring length was the elbow length. One cubit was equal to seven palms, one palm to four fingers. 


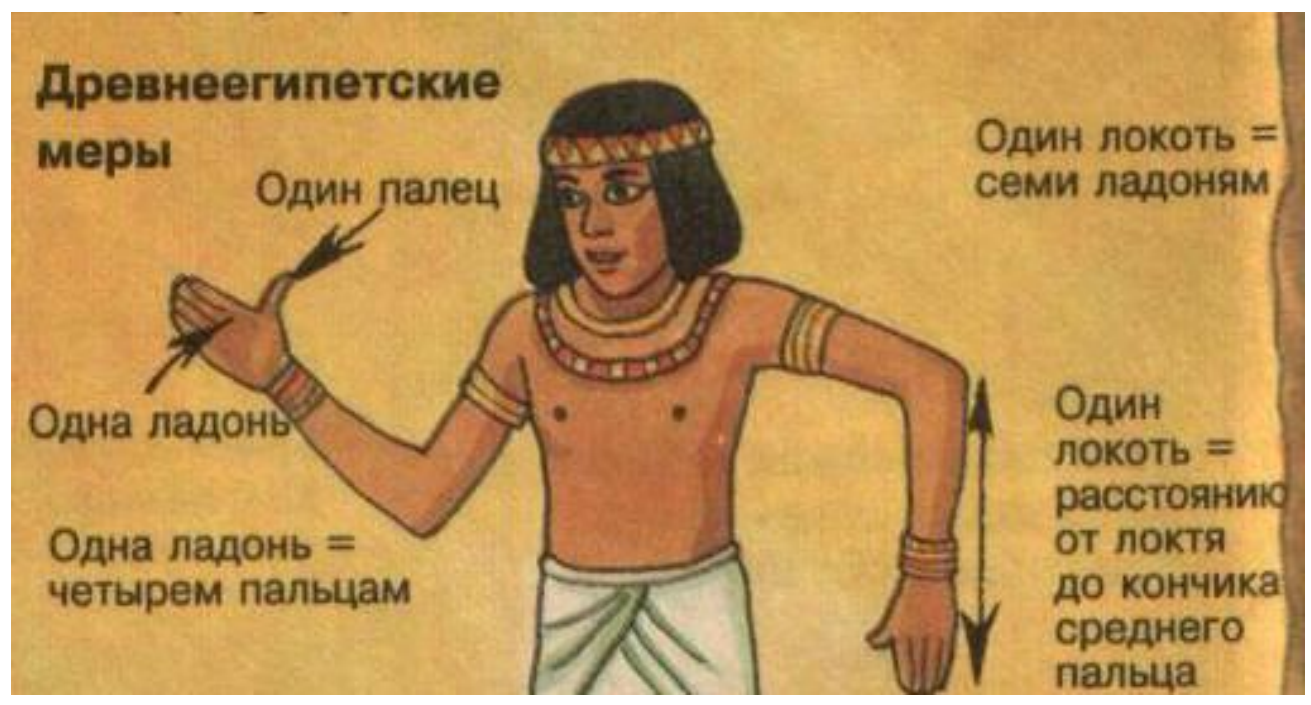

When studying the topic of length units, it is recommended that you show the teacher how you can measure the length of the tape using your elbow. He then invites several students to measure the same tape length in the same way. Since the length of the elbow is different for guys, of course, the result will be different. This needs to be analyzed. That is why a single standard was adopted in ancient Egypt, i.e. a peculiar image of the size of the elbow, palm, and finger.
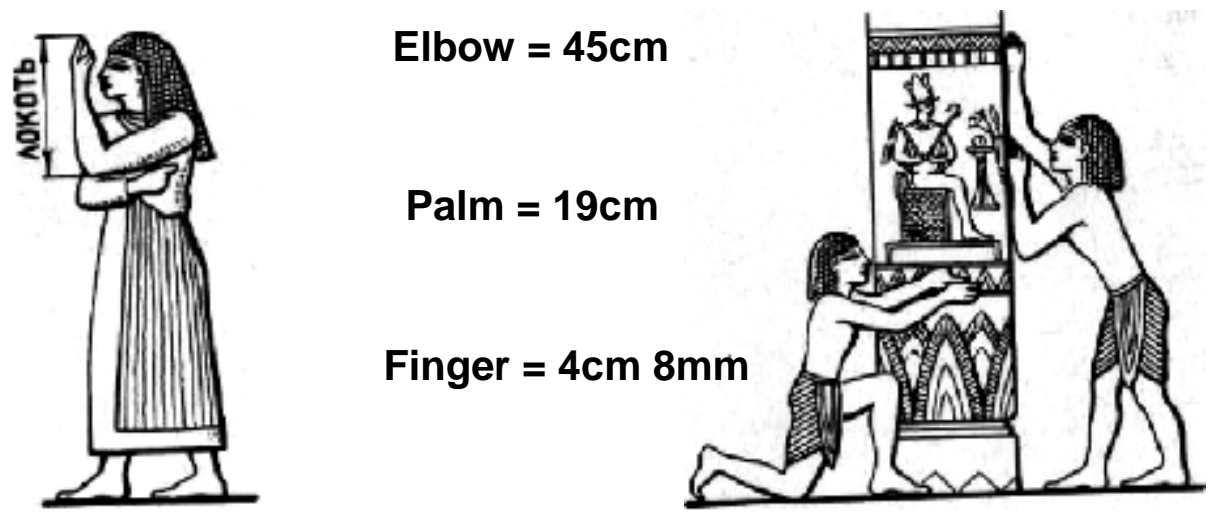

Measuring lengths with elbows and fingers 


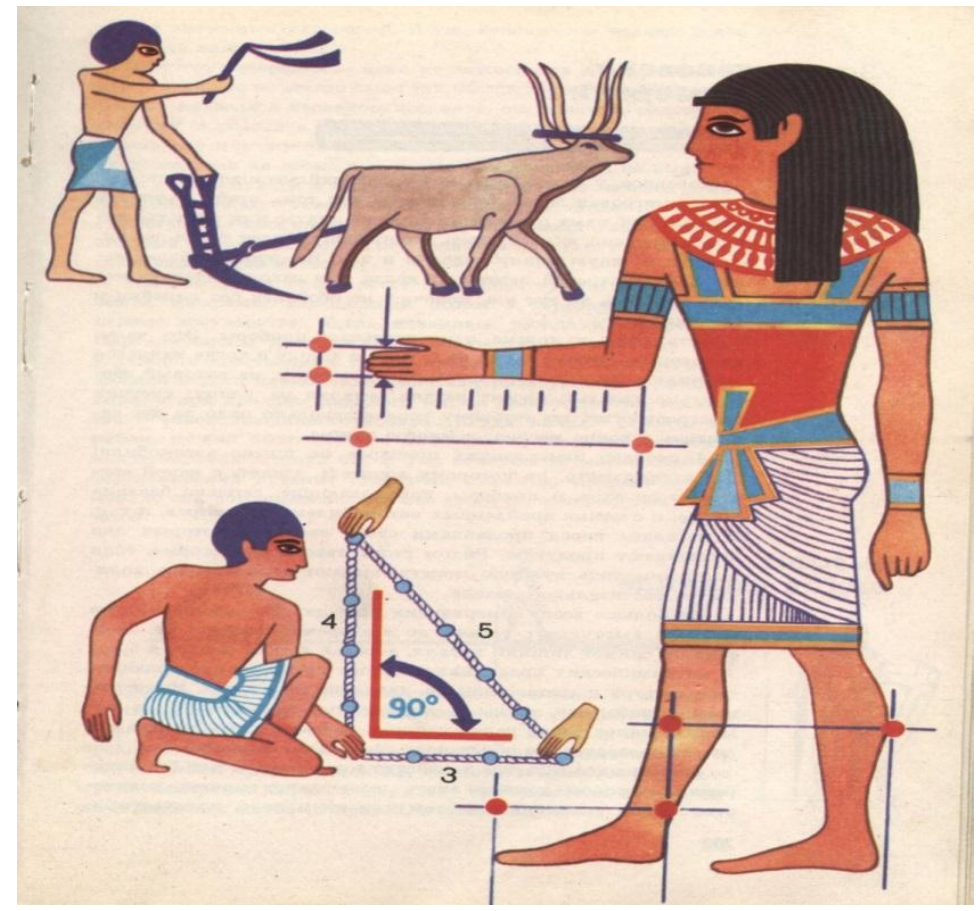

In England, units of length related to body parts were also used. For example, an inch - (in Dutch "thumb") is equal to the length of three grains of barley. Taken from the middle of a barley ear.

An inch is the length of the first phalanx of the thumb.

$$
\text { Inch }=2 \mathrm{~cm} \mathrm{5mm}
$$
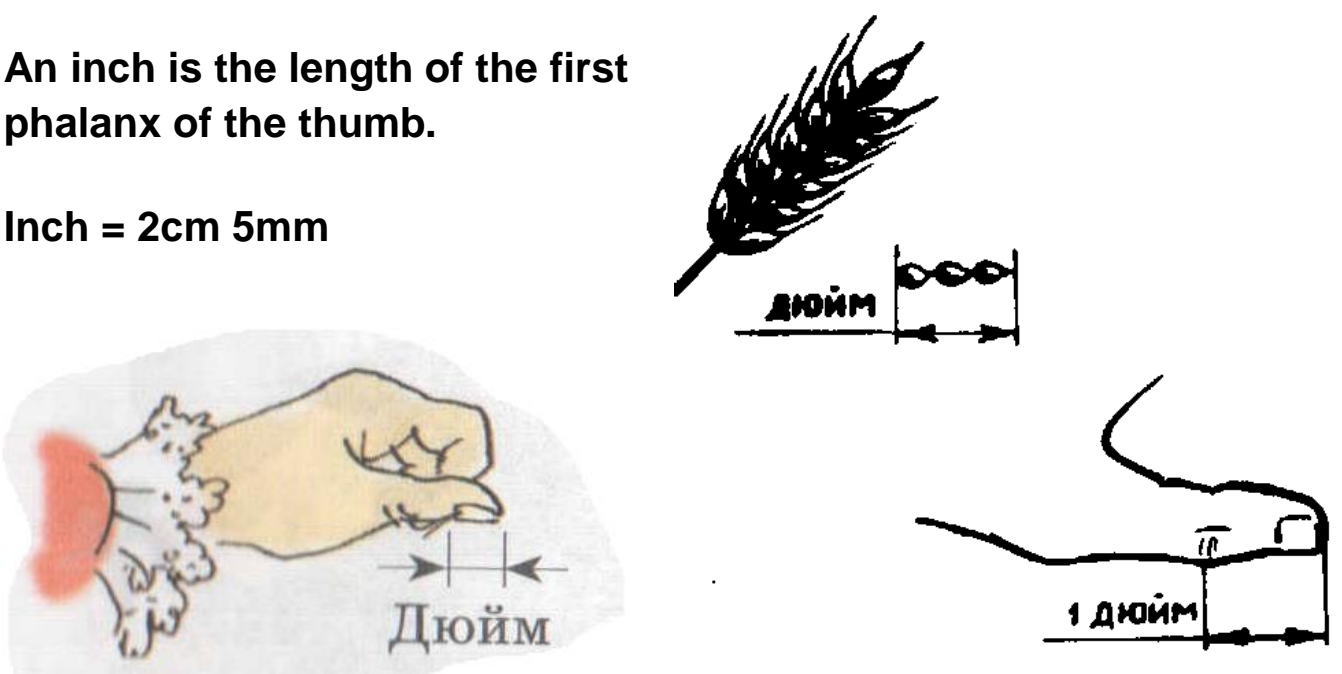


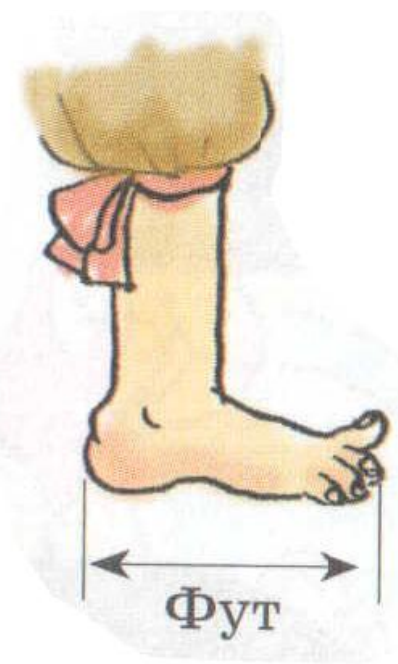

Foot is the foot of the

leg.

Foot $=12$ inches

Foot $=30 \mathrm{~cm} 48 \mathrm{~mm}$
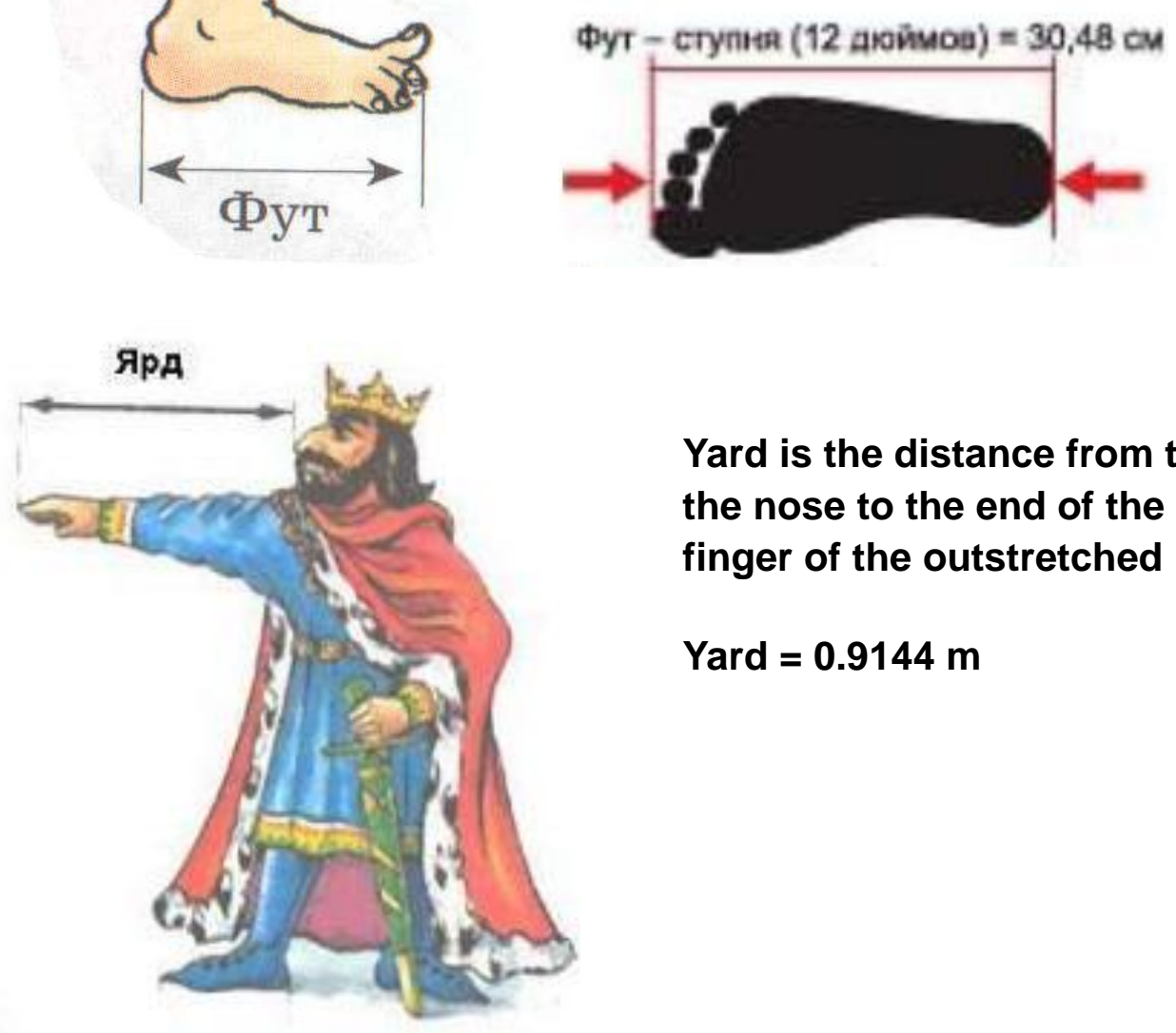

Yard is the distance from the tip of the nose to the end of the middle finger of the outstretched hand.

Yard $=0.9144 \mathrm{~m}$

Ancient measures of length in England

In the countries of Central Asia, since ancient times, various units of measurement have been used. The currently approved units of measurement of quantities were introduced in 118. But until now in literature and everyday life there are such units of length measurement as "batman", "miskal", "tanab", "gas", "karich" (distance between thumb and little finger), "chakirim" (verst) other.
The following units of length were used in Uzbekistan. "Gas" - in different areas, this unit of measurement has been interpreted in different ways. Usually, "gas" is analogous to a measure of length known as the cubit. The value of this measure has changed many times. So, in the Middle Ages, 1 gas was equal to $62 \mathrm{~cm}$, later, depending on the region, its value varied from 68 to $96 \mathrm{~cm}$. The most common gas lengths were 61 and $106 \mathrm{~cm}$. 
In addition, there were such units of length measurement as "farsak" (the length of six pieces of barley grains), kulach (that is, the swing of the hand), karich, suyak, etc.

For example, "Meradlina Markhala" is a distance unit equal to $46 \mathrm{~km}$.

"Farsahili farsang" is a classical measure of length, consisting of $3 \mathrm{mil}$ and equal to $6 \mathrm{~km}$. But, as usual, these values varied in Central Asia. In particular, in some regions this distance was measured in steps and was equal to 12 thousand steps. In general, the value of this measure varied from 5.6 to $8.5 \mathrm{~km}$.

"Angusht" is a small measure of length equal to the width of the middle joint of the bent toe. The classic angusht was usually expressed as equal to the total thickness of 6 grains of barley, laid side by side, with the thickness of each grain equal to the width of 6 hairs from the mane of a working horse. The Türkic analogue of Angushta - barmak - had a value of 2.18 and $2.28 \mathrm{~cm}$.

From the history of mass measurement, in the course of its development, mankind faced the need to exchange, sell food (grain, meat), animals, products of their labor, etc.

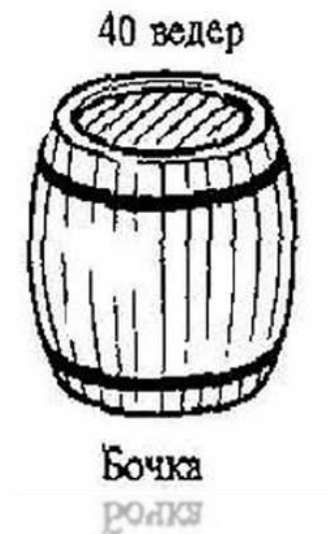

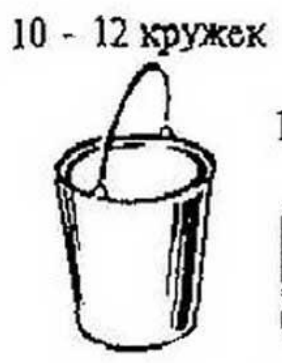

Beapo
1 Литง

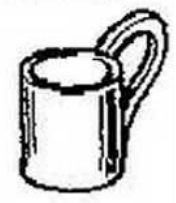

Borfho

ar - the area of a square, the side length of which is $10 \mathrm{~m}$;

Liter - volume and capacity of liquids and bulk solids equal to the volume of a cube with an edge length of $0.1 \mathrm{~m}$;

Gram is the mass of pure water that occupies the volume of a cube with an edge length of $0.01 \mathrm{~m}$.

Loose and liquid products were measured by people using various containers - buckets, vessels, sieves, etc.

Then the idea arose to measure the quantity of goods by weight, i.e. by mass. Thus, the
But to measure the quantity, for example, the order of materials, metal, it was impossible to use this method.

scales appeared. In Ancient Egypt, lever scales were used before our era. 


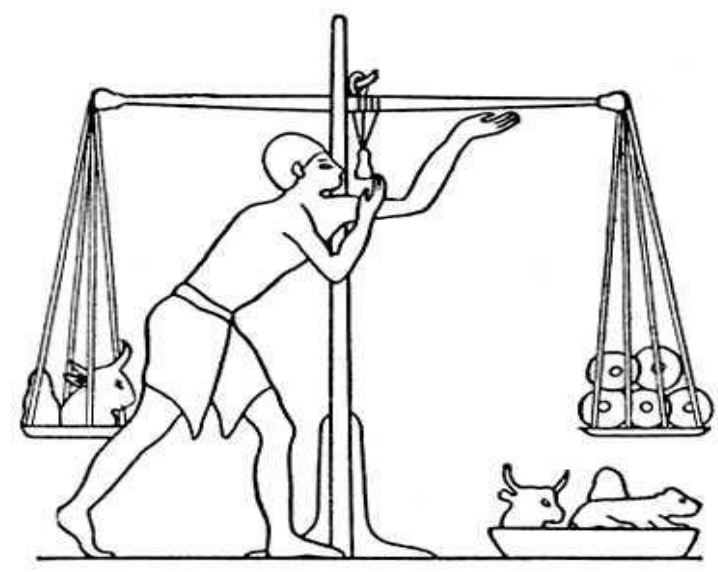

In Uzbekistan, the following units of mass were used:

"Batman": - in literary sources is found as “mann". In everyday life, batman - a measure of weight, was very common in Central Asia and had several meanings. The Turkestan batman was about $128 \mathrm{~kg}$, the Tashkent batman - 160-190 kg, the Bukhara batman about $120 \mathrm{~kg}$.

"Mann" is a very important measure of mass (weight) in a number of Muslim countries, on the basis of which a whole system of measurements was built. Historically, mann dates back to the ancient mine. The exact meaning of manna has fluctuated with place and time. The weight of the most common manna in Khorezm and Khiva ranged from 4.095 to $4.914 \mathrm{~kg}$, and in Bukhara there were several values of manna of $25.6 \mathrm{~kg}, 20 \mathrm{~kg}$ and $128 \mathrm{~kg}$ at once.

"Dunismir" is one of the measures of units of weight in the system of multiples of manna. It was equal to $1 / 16$ manna and depended only on the value of the manna itself in a certain region. For example, in Bukhara, dunismir, depending on the size of manna, ranged from $54 \mathrm{~g}$ to $8 \mathrm{~kg}$.

"Yasirak" is also one of the units of weight in the manna system, used in Samarkand, Shakhrisabz, Ura-Tyube and other cities. The average yasirak was $256 \mathrm{~g}$. But in the areas of the valley of the Pyanj or Obi Garm rivers, its value reached 1.25 or even $5 \mathrm{~kg}$.

The unit of weight "pais" was very used from Fergana to Khujand. Information from sources of the XIX century show that the size of the pice was not the same in different periods and at different times had several options. In Khujand and Namangan, the pice was $25.6 \mathrm{~g}$.

"Daksari" is a unit of measurement equal to one fourth of the batman.

"Miskal" is a measure of body weight that was in use from Iran to China. In the region of Samarkand and Penjikent in the VI-VIII centuries its size was 4, $46 \mathrm{~g}$. In late medieval Bukhara, there were generally two meanings of miskal -4.8 and $5 \mathrm{~g}$. Miskal was the basis for the weight of silver and gold, as well as the minting of coins in the 16th -18 th centuries. In the metric system of measurement, this measure today has the equivalent of $10 \mathrm{~g}$.

"Ser" (sir) is a unit of mass measurement widely used in the countries of Central Asia, equal to $1 / 40$ of a botmon.

"Chaksa" - this unit of measurement was widely used in the Fergana Valley. In Namangan, 1 chaksa is $5.3 \mathrm{~kg}$, in Kokand - 4.6 $\mathrm{kg}$. In addition to them, in the countries of Central Asia, such units of mass measurement 
as "arpa" (0.05 kg), kadon (409.5 grams) and others were used.

\section{CONCLUSION}

To measure the area, the unit of measurement in Central Asia was "tanab". It is an area of a square with a side of 60 gases (i.e. 3600 square meters of gas). One tanab in Khorezm is equal to 4037 square meters, in the vicinity of Tashkent - 18209 square meters, in Surkhandarya - 2733 square meters.

Household items were often used as measures of weight. For example: cap (bag) - as a measure of the volume of bulk solids in the northeast of Central Asia and in Kazakhstan, equaled $64 \mathrm{~kg}$, bowl - 320 cubic meters. cm. A small tabak (dish) was used as a measure of the volume of bulk solids and was equal to 4 $\mathrm{kg}$. Large tabak is already $12 \mathrm{~kg}$, and also had a value - $16 \mathrm{~kg}, 21 \mathrm{~kg}, 26.5 \mathrm{~kg}$. Taki (skullcap) is a measure of the volume of bulk solids, equal to $1.33 \mathrm{~kg}$.

To successfully teach mathematics to primary school students, a novice teacher must master the already developed system of teaching mathematics and, on this basis, begin creative independent work.

\section{REFERENCES}

1. Mirziyoev Sh. M. Critical analysis, strict discipline and personal responsibility should be the daily rule of every leader's activity. Report of the enlarged meeting of the Cabinet of Ministers on the main results of socioeconomic development of the country in 2016 and the most important priorities of the economic program for 2017, January 14, 2017 Tashkent: Uzbekistan, 2017. -p. 104.

2. Mirziyoev Sh. M. The rule of law and the protection of human interests are the key to the country's development and the well-being of the people. Speech at the solemn ceremony dedicated to the 24th anniversary of the adoption of the Constitution of the Republic of Uzbekistan. December 7, 2016- Tashkent: Uzbekistan, 2017. p.48.

3. Programs and textbooks of primary school mathematics. Adopted in the republic, teaching aids for teachers, didactic materials for students.

4. Javlieva G.R. Didactic basis for the use of historical materials in improving the effectiveness of primary school mathematics lessons (monograph). Tashkent: 2019.

5. Javlieva G.R. Didactic bases of the use of historical materials in increasing the effectiveness of primary school mathematics lessons. Study guide. Tashkent: 2007.

6. Javlieva G.R Development of productive thinking in younger students. Professional education and society. 2019. No. 4 (32). -p. $116-130$.

7. Jumaev E.E. Theory and methodology of elementary mathematics. (For KXK) Tashkent. "Turon-Iqbol" 2012.

8. Talashev Kh.Kh. General pedagogical and didactic ideas of educational encyclopedists of the near and Middle East of the Middle Ages. Tashkent. Ed. "Fan" 1980. 